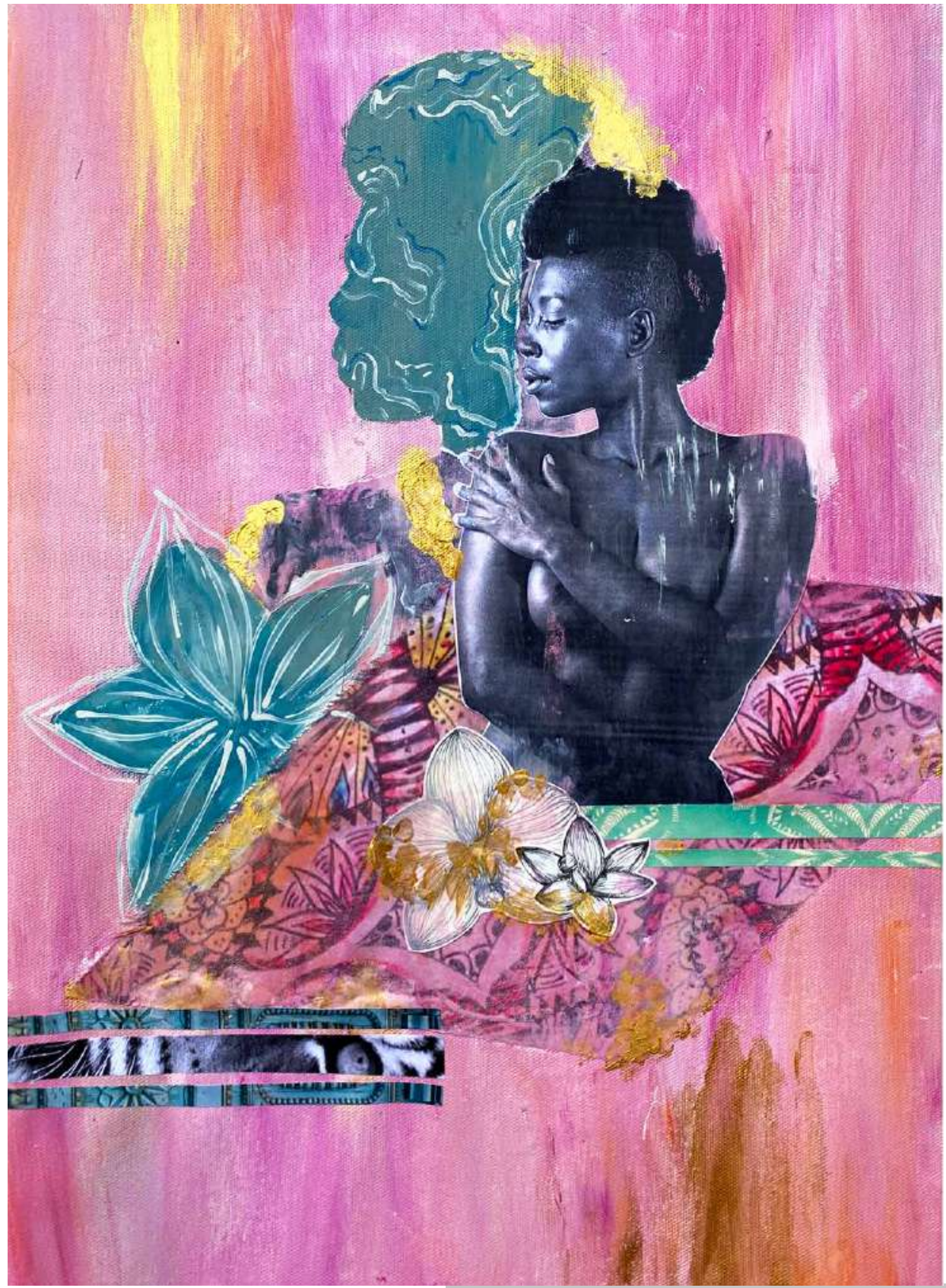

Artista invitada

Sofía Baraya Llaña

Jeli Pink

De la serie Ya no son chucherías

Técnica mixta

Fecha: 2020

Cortesía Revista Ojo de Pez 


\section{Laó-Montes, Agustín. (2020). Contrapunteos diaspóricos. Cartografías políticas de nuestra Afroamérica. Bogotá, D. C.: Universidad Externado de Colombia.}

\section{Resumen}

Este libro aborda desde una perspectiva política, sociológica y cultural decolonial los discursos liberadores de saber y poder que las subjetividades del mundo afrodiaspórico han legado a la humanidad, en aras de su reivindicación intelectual y ciudadana frente a los prejuicios étnicos y raciales, rescatando el legado cultural y social de la afrodiáspora a la humanidad. Para ello usa un marco teórico que desarrolla categorías y cosmovisiones socio comunitarias propias, con el fin de fundamentar la construcción de sociedades más justas, equitativas y democráticas. En suma, es una narración poética que evoca el malungaje de Jerome Branche, al atlántico negro de Gilroy y al discurso antillano de Éduard Glissant.

\section{Palabras clave}

Decolonialidad; Subjetividades; Epistemología; Estudios Afroamericanos; Afrodiáspora.

\section{La sociología decolonial de Agustín Laó-Montes}

Es posible decir que en este imponente libro, que está organizado en catorce capítulos divididos en tres partes, el arte musical ocupa un lugar preponderante. Quizá los orígenes puertorriqueños del autor incidan en que el ritmo musical del Caribe se deje leer y escuchar a lo largo de las 562 páginas del texto. Esta obra resulta ser una sociología artística decolonial que apropia expresiones como «tocando ese mambo», «bailando ese mismo ritmo» y «siguiendo ese mismo son» para ambientar poéticamente su gran epopeya decolonial de las luchas políticas, sociales y culturales a la que él denomina contrapunteos diaspóricos o cartografías políticas decoloniales de nuestra Afroamérica. Esa pasión por la música plasmada en el trabajo es porque el autor ha sido guiado por sus ancestros, orichas y babalaos, razón por la que ha hecho del tambor, del ritmo y de la música el objeto predilecto para escribir un libro estético y poético, una bellísima pieza de escritura que desde ya puede adquirir la categoría de clásico en el ámbito de las genealogías, arqueologías sociales y racialidades afrodiaspóricas. 
Pero, zquién es Agustín Laó-Montes? Es un doctor en Sociología puertorriqueño, de esa pequeña isla que hoy se hace presente ante el mundo decolonial con reputados pensadores como Ramón Grosfoguel y Nelson Maldonado Torres, quienes irradian desde connotadas y reconocidas universidades norteamericanas y en sus libros, obras y reflexiones las semillas de las narraciones y del pensamiento propio de América, siendo así herederos de la tradición libertaria caribeña de grandes pensadores como José Martí, Frantz Fanon, Aimé Césaire y Eugenio María de Hostos. No solo eso, en LaóMontes se advierten las influencias de pensadores europeos como Michel Foucault, a los que el autor reconoce un marco conceptual clave a través de nociones como genealogías, arqueologías, microfísica y dispositivos de saber-poder, que luego él contextualiza desde una perspectiva de los saberes-otros de las subjetividades, geografías y espacios del actuar y pensar de las intelectualidades e identidades de los sujetos, en lugares cartográficos afrodiaspóricos. Esas influencias nos dan cuenta del carácter epistemológico de este clásico que nos ha regalado el doctor Laó-Montes, que escribe para el mundo a través de sus genealogías, arqueologías y contrapunteos en su clave decolonial, articulándose a las redes de los movimientos sociales, políticos y culturales de Afroamérica.

Otra de las grandes influencias del texto está dada por referentes del pensamiento crítico de América Latina como Enrique Dussel, a través de quien se introduce en categorías como locus de enunciación y transmodernidades que permiten hacer la gran analéctica del poder-saber desde una perspectiva de subjetividades afrodiaspóricas, una línea en la que estarían como maestros e interlocutores de Laó-Montes, Boaventura de Sousa Santos, Walter Mignolo, Aníbal Quijano, Fernando Coronill y, especialmente, Fernando Ortiz, quien con sus categorías de «contrapunteos»y «transculturación»es el autor que más influye en esta agencia decolonial. Por ello es que el autor puertorriqueño es desde ya un clásico del pensamiento crítico de América Latina y del Caribe, puesto que asume nociones originales y propias para el estudio de las identidades culturales, políticas y raciales del movimiento afro en el mundo, esquemas conceptuales como «metodología contrapuntual», «razón cimarrona», «analéctica del poder-saber», «afromodernidades», palabras, términos y expresiones que inauguran una nueva interpretación de las luchas étnicas, reivindicativas, sociales y culturales de los sujetos afrosnegros-cimarrones, afrodescendientes, afrodiaspóricos y afrolatinos. 
Ahora bien, es importante profundizar en tres puntos que considero cardinales para entender la quintaesencia del libro y sus ideas fundamentales: el primero hace referencia al proyecto libertario haitiano a partir de la lectura que hace Laó-Montes —siguiendo a M. R. Trouillot, C. L. R. James y S. Fischer- del carácter libertador de lo que se produjo en esta pequeña isla antillana entre 1791 y 1804, donde sujetos, ciudadanos afro, hicieron una revolución política que rompió los esquemas convencionales de interpretación del mundo moderno, pues todas las lecturas hechas al evocar esa categoría de la revolución y del antiguo régimen se apuntalan si y solo si en la Revolución Francesa -1789- y en la Independencia de los Estados Unidos -1776-. Pero a partir de aquí podemos pensar en modernidades afro y reinterpretar política y sociológicamente este fenómeno a través de figuras afro como Toussaint Louverture, Henry Cristophe, Alexandre Petión, Jean-Jacques Dessalines, antecedidos por Francois Mckandal y Dutty Boukman, quienes conciben, piensan y realizan un proyecto emancipador de subjetividades negras en un espacio y tiempo-otro caribeño que rompe con todas las lógicas greco-occidentales de concebir y hacer un proyecto político y revolucionariootro. Desde la sociología decolonial de Agustín Laó-Montes esto se podría denominar transmodernidad o afromodernidad-otra, un proceso complejo en el que los afros hicieron reformas políticas, agrarias, sociales y que pensaron la libertad, la ciudadanía y la independencia de América y de sus colonias mucho antes que otros personajes más reconocidos como Simón Bolívar.

El segundo punto hace referencia a lo que Agustín Laó-Montes denomina «analéctica racial», «capitalismo racial» y «regímenes raciales» para estudiar desde la arqueología y la genealogía —siguiendo a W. E. B. Du Bois- cómo la categoría de raza se configuró en el siglo xx en un paradigma e imaginario para analizar las lógicas de funcionamiento de los Estados. Considero que este tema que recorre todo el libro hoy más que nunca reviste una importancia crucial por los problemas raciales que se presentan en nuestras sociedades, reflejados especialmente en los recientes hechos acontecidos en Estados Unidos y en otros países, donde pensábamos que el odio al otro, al extranjero y al emigrante habían desaparecido. Hoy, cuando resurgen los prejuicios y estereotipos raciales de superioridad y prevalencia de determinados fenotipos físicos y corporales como ideales de humanidad, de sociedad y de hombres y mujeres estimulados por líderes xenófobos y racistas, es imprescindible más que nunca resistir intelectual, cultural y teóricamente para derrubiar esos viejos clichés apuntalados en añejos esquemas mentales que pensábamos 
que ya estaban fosilizados y enterrados en los anales de la historia. Hoy más que nunca es imprescindible la lucha contra el racismo, la xenofobia y las clases elegidas, característicos de ciertos Estados y regímenes políticos en la actualidad que lo venden como una ideología, haciendo que unos hombres armados — su fuerza legítima materializada en policías y fuerzas armadasconsideren que esos otros cuerpos no valen absolutamente nada.

Las luchas y resistencias contra estos mitos, prejuicios y estereotipos deben continuar en las calles y en el campo de la movilización política propiamente dicho, es lo que vemos hoy en Estados Unidos cuando reaparecen las grandes movilizaciones como en la época de los derechos civiles de la década de 1960. La sociedad civil americana y la ciudadanía mundial debe estar siempre vigilante contra estas carimbas que esclavizan y limitan la verdadera ciudadanía plural y diversa del planeta, las cuales impiden que comprendamos que parte de nuestra ciudadanía está en los otros, en la lucha de las mujeres por afirmar sus identidades y diversidades, y en los movimientos de los jóvenes para afirmar sus gustos y costumbres-otras.

El tercer punto se puede pensar desde la perspectiva de lo que Agustín Laó-Montes ha denominado «cartografías del campo político afrodescendiente [360] en América Latina», haciendo un estudio genealógico y arqueológico en clave decolonial, afrolatina y caribeña para hablarnos de una serie de redes, proyectos, actores y subjetividades que se han constituido en voceros de un proyecto cultural y político en Afroamérica, entre los que están los movimientos de la negritud de Césaire y Fanon, el Renacimiento negro de Harlem, el Frente Negra Brasileira, el movimiento Niágara liderado por Du Bois y el movimiento cubano negro, sin olvidar las cumbres de las américas negras que convocaron en su momento Manuel Zapata Olivella, Gerardo Maloney y el Cheche Campo con el fin de perseguir la unidad cultural de Afroamérica. Hoy, estas iniciativas se pueden resumir en la ola de movimientos antisistémicos de la afrodiáspora, los cuales incluyen afrofeminismos, marxismos negros y todos los movimientos identitarios y raciales que surgen contra la hegemonía y el capitalismo global. Cada uno de estos movimientos decoloniales ayudó a definir a Afroamérica, que a través de una serie de procesos como las cumbres, redes, asociaciones y congresos de intelectuales negros ayudan a estructurar lo étnico y la etnicidad de las luchas por la igualdad cultural, política y social en todo el mundo afrodiaspórico.

El tema de los movimientos sociales afrodiaspóricos, según Laó-Montes, permite reconocer una serie de líderes, intelectuales y militantes como Arturo 
Alfonso Schomburg en Puerto Rico, Romero Rodríguez en Uruguay, John Antón Sánchez y Claudia Mosquera en Colombia, Leila González y Sueli Carneiro en Brasil, Jesús García en Venezuela, Epsy Campbell y Quince Duncan en Costa Rica, y el reciente Black Lives Matter en Estados Unidos con lideresas como Keeanga-Yamahtta Taylor, quienes han estado redefiniendo la sociología política convencional, pues aquí tenemos otras subjetividades, otros discursos, otras narrativas de lo político y de la política, y pensar la acción social desde el quehacer afro es otro modo de entender la sociedad y la cultura política.

Se puede decir también que este libro es un llamado a crear redes de solidaridad y fraternidad para conformar una nueva humanidad desde categorías afrodiaspóricas como muntu, ubuntu y uramba, buscando crear palenques planetarios y futuros decoloniales de liberación desde la afrodiáspora, pero también desde una perspectiva de liberación psíquica, mental, intelectual y socioeconómica en aras de un mundo justo y equitativo para todos los seres que lo habitan, he allí el llamado a la solidaridad, a la fraternidad y a un humanismo ambientalista afrodiaspórico desde la filosofía y el pensamiento muntu:

Aquí buscamos definir una perspectiva epistémica que nos permita estudiar y explorar las condiciones de posibilidad y los procesos constitutivos de la racialidad como elemento central de la matriz de poder moderna/colonial que configura el sistema-mundo capitalista en su larga duración. Entonando ese son dibujaremos un marco categorial y referentes teóricos y metodológicos para elaborar una analítica, para conceptualizar e investigar las formaciones étnico-raciales, el racismo en su pluralidad y complejidad y la política racial como el elemento más dinámico y transformador de la cuestión étnico racial (p. 88).

Y por ello el horizonte del trabajo de Laó-Montes es indagar en «cómo combatir cadenas de colonialidad y opresión, con lazos de solidaridad para la liberación» (p. 137).

William Mina Aragón (Colombia)*

\footnotetext{
* Licenciado en Filosofía. Doctor en Sociología y Ciencias Políticas. Profesor titular del programa de Ciencia Política y miembro del grupo de investigación Actores, Procesos e Instituciones Políticas (GIAPIRP), Universidad del Cauca, Colombia. Correo electrónico: williammina@hotmail.com Orcid: https://orcid.org/0000-0002-4875-9740
} 